
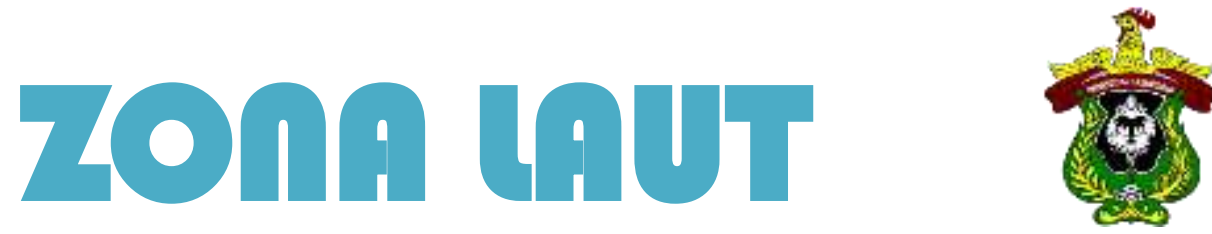

\title{
ANALISIS PELETAKAN DAN KEBUTUHAN PROTEKSI KATODIK PADA MOORING BUOY DI PERTAMINA FUEL TERMINAL LUWUK
}

\author{
*Habibi Palippui, Juswan Sade dan Windi Widianingrum \\ Departemen Teknik Kelautan Universitas Hasanuddin \\ *windian12@gmail.com
}

\begin{abstract}
Abstrak
Korosi adalah salah satu penyebab kerusakan yang umum terjadi pada mooring buoy akibat adanya oksidasi pada permukaan pelat baja. Tujuan dari penelitian ini adalah untuk mengetahui kebutuhan dan peletakan proteksi katodik serta biaya yang dibutuhkan dalam pengadaan proteksi katodik pada mooring buoy dengan menggunakan aturan BKI (Biro Klasifikasi Indonesia) dan DNV (Det Norske Veritas Industry Norway). Dalam sistem proteksi katodik terdapat dua metode proteksi katodik yaitu Sacrificial Anode Cathodic Protection (Anoda Korban) dan Impressed Current Cathodic Protection (ICCP). Pada penelitian ini digunakan metode anoda korban karena instalasi lebih sederhana sehingga tidak memerlukan keahlian khusus dan penghubung anoda telah terlindungi secara katodik. Mooring buoy dengan tinggi 2,380 $\mathrm{m}$, berdiameter 3,200 meter dengan umur desain proteksi katodik yaitu 5 tahun. Anoda yang digunakan pada penelitian ini adalah anoda dengan tipe Longated flush-mounted Z9.0H1 (Welded Type) dengan dimensi 355 x 85 x 45 mm. Dari hasil penelitian ini didapatkan total massa anoda yang dibutuhkan untuk memproteksi mooring buoy adalah $48 \mathrm{~kg}$ dengan jarak pemasangan antar anoda pada pelat lambung topside adalah $2,000 \mathrm{~m}$ dan pada pelat bottom swim lambung adalah 3,000 m serta estimasi biaya yang dibutuhkan dalam pengadaan proteksi katodik mooring buoy adalah Rp. 7.487.075.
\end{abstract}

Kata Kunci: Mooring Buoy, Korosi, Zinc Anode.

\begin{abstract}
Abstrct
Corrosion is one of the most common causes of damage to mooring buoys due to oxidation on the surface of the steel plate. The purpose of this study was to determine the need and placement of cathodic protection as well as the costs involved in providing cathodic protection for mooring buoys using the rules of BKI (Indonesian Classification Bureau) and DNV (Det Norske Veritas Industry Norway). In the cathodic protection system, there are two methods of cathodic protection, namely Sacrificial Anode Cathodic Protection (SACP) and Impressed Current Cathodic Protection (ICCP). In this study, the Sacrificial Anode method was used because the installation is simpler so that it does not require special skills and the anode connector is cathodically protected. Mooring buoy 2.380 meters high, 3.200 meters in diameter with a cathodic protection design life of 5 years. The anode used in this study was a Longated flush-mounted Z9.OH1 (Welded Type) anode with dimensions of $355 \times 85 \times 45 \mathrm{~mm}$. From the results of this study, the total anode mass needed to protect the mooring buoy is $48 \mathrm{~kg}$ with the distance between the anodes on the topside hull plate is $2.000 \mathrm{~m}$ and the hull bottom swim plate is $3.000 \mathrm{~m}$ and the estimated cost required in providing mooring buoy cathodic protection is $R p .7,487,075$.
\end{abstract}

Keywords: Mooring Buoy, Corrosion, Zinc Anode.

\section{PENDAHULAN}

Struktur bangunan laut (kapal, anjungan lepas pantai, pipa bawah laut dan bangunan apung lainnya) yang beroperasi tidak terhindar dari proses korosi. Sehingga, manajemen perawatan pada suatu struktur bangunan laut sangatlah penting karena biaya pembangunan dari struktur tersebut mahal. Dilihat dari segi konstruksinya, bagian yang rentan tedampak korosi adalah area yang terkena air laut seperti pada konstruksi bagian hull. Korosi pada pelat dapat mengakibatkan menurunnya kekuatan dan umur pakai suatu bangunan laut. Pertamina Fuel Terminal (PFT) Luwuk merupakan Terminal Bahan Bakar Minyak (TBBM) yang termasuk dalam wilayah operasi PT. Pertamina (Persero) Marketing Operation Region (MOR) VII Sulawesi. Dalam menunjang copyright is published under Lisensi Creative Commons Atribusi 4.0 Internasional. 
proses distribusi agar tetap berjalan lebih baik perlu di dukung dengan sarana dan fasilitas yang memadai salah satunya adalah mooring buoy sebagai sarana tambat dalam proses loading dan unloading muatan kapal. Mooring buoy yang beroperasi tentunya akan mengalami proses korosi. Akibatnya akan terjadi penurunana ketebalan pelat baja dan efektivitas kerja mooring buoy sebagai alat tambat.

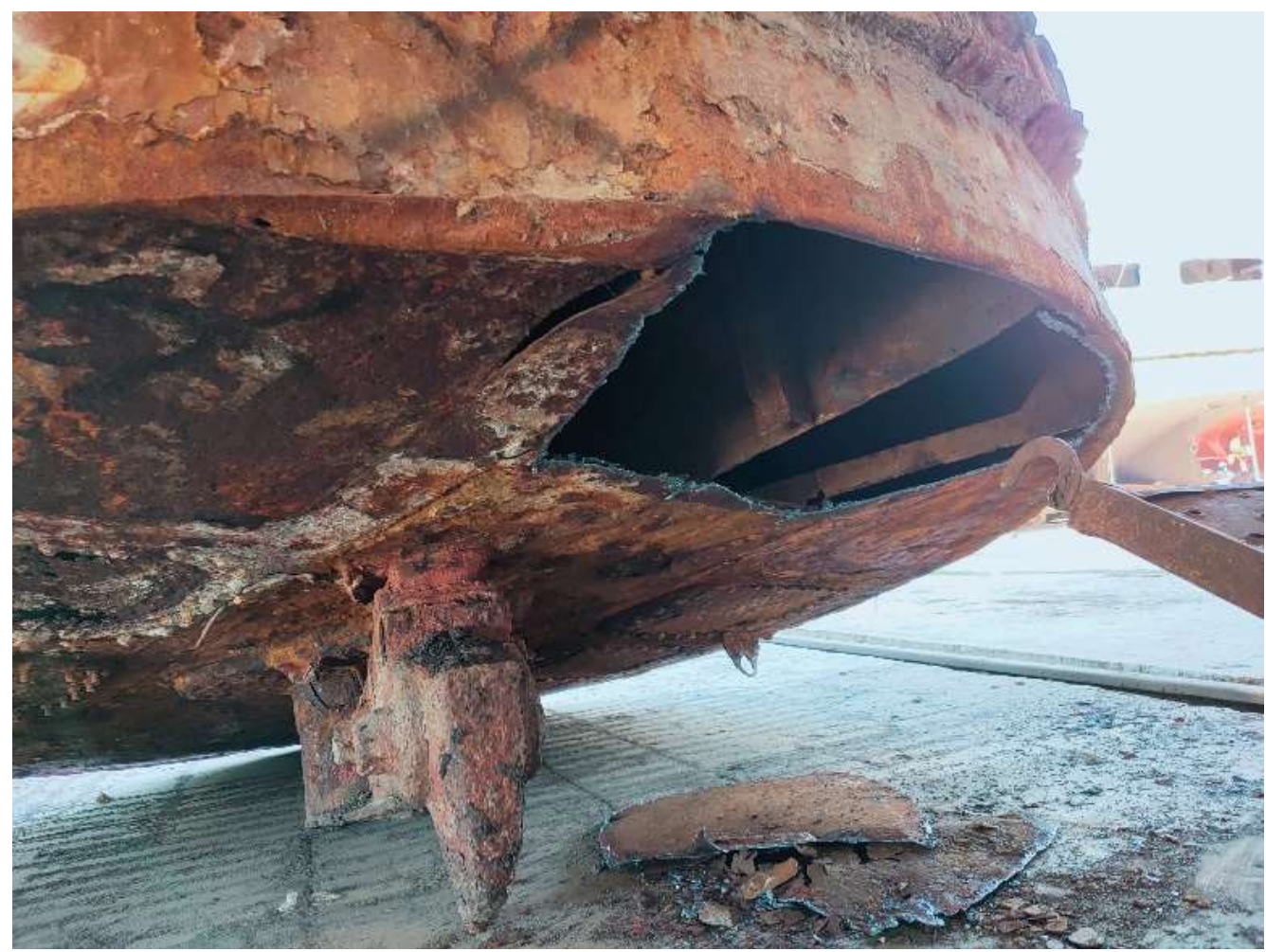

Gambar 1. Korosi yang terjadi pada pelat mooring buoy

Metode penanggulangan korosi dapat digunakan salah satu solusi yaitu dengan cara melindungi pelat secara berkala menggunakan proteksi katodik (cathodic protection). Proteksi katodik merupakan salah satu metode teknologi pengendalian korosi dengan membalikkan arah arus korosi. Metode ini merupakan manajemen perawatan konstruksi bangunan laut dengan menjadikan permukaan pelat tersebut sebagai katoda dari sel elektrokimia [1].

Oleh karena itu pada penelitian ini ini akan membahas mengenai perencanaan kebutuhan sistem proteksi katodik pada mooring buoy milik Pertamina Fuel Terminal Luwuk. Selain perencanaan kebutuhan proteksi katodik, perencanaan pemasangan/peletakan proteksi katodik di analisis pada penelitian ini.

\section{METODE}

Korosi juga di definiskan sebagai penurunan kualitas logam akibat reaksi elektrokimia dengan lingkungannya [2]. Korosi terjadi dalam berbagai macam bentuk, mulai dari korosi merata pada seluruh permukaan logam sampai dengan korosi yang terkonsentrasi pada bagian tertentu saja. Proteksi adalah sebuah penanganan guna melindungi suatu benda dari hal yang dapat merusak sehingga benda tersebut tidak dapat berfungsi secara optimal. Dalam hal ini proteksi pada dunia industri sangat dibutuhkan karena memiliki fungsi untuk melindungi suatu struktur, salah satu proteksi yang digunakan adalah proteksi katodik untuk melindungi struktur dari korosi. Proteksi katodik dengan menggunakan anoda korban terjadi saat logam dihubungkan dengan logam yang lebih reaktif (anoda). Hubungan ini mengarah pada sebuah rangkaian galvanic. Untuk memindahkan korosi secara efektif dari struktur logam, material anoda harus mempunyai beda potensial cukup besar untuk menghasilkan arus listrik [3].

\subsection{Objek Penelitian}

Pemasangan mooring buoy milik PT. Pertamina (Persero) ini akan dioperasikan di Luwuk, Sulawesi Tengah sebagai salah satu fasilitas penunjang dalam proses penambatan dan loading bahan bakar minyak. Desain copyright is published under Lisensi Creative Commons Atribusi 4.0 Internasional. 
perlindungan katodik pada mooring buoy yang digunakan berdasarkan Biro Klasifikasi Indonesia dalam Regulation for the Corrosion Protection and Coating System. Sistem perlindungan katodik yang akan digunakan adalah Longated flush-mounted (Welded Type) seperti yang dapat dilihat pada gambar berikut.

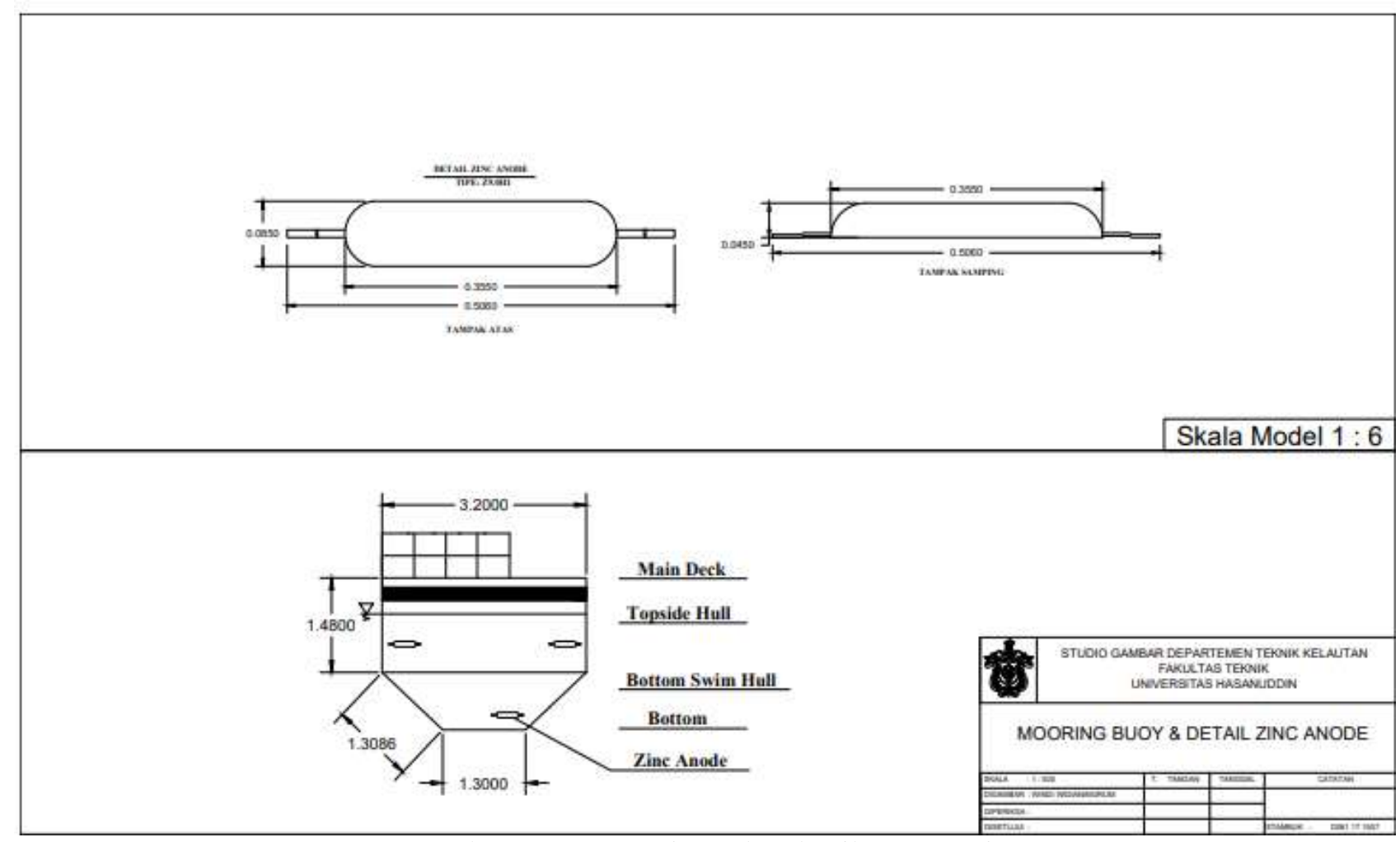

Gambar 1. Mooring buoy dan detail zinc anode

\subsection{Metode Anode Korban}

Secara sederhana metode ini menggunakan logam baru yang memiliki level energi yang lebih tinggi sehingga tercipta arus yang mengalir dari logam yang paling rendah ke yang lebih tinggi. Namun anoda tersebut memiliki batas umurnya dimana anoda tersebut akan sepenuhnya terkontaminasi dan harus diganti dengan yang baru. Cara kerja perlindungan katodik dengan anoda korban adalah menggunakan konsep tentang sel korosi basah. Bahwa dalam sel anodalah yang berkarat atau korosi, sedangkan tidak tidak terkorosi adalah katoda. Anoda yang terhubungkan ke struktur dengan tujuan mempengaruhi perlindungan terhadap korosi, dengan cara ini disebut anoda korban. Adapun keunggulan dari metode ini adalah sebagai berikut:

a. Dapat digunakan tanpa membutuhkan energi listrik dari luar

b. Hampir tidak memerlukan pengawasan, biaya menjadi relative lebih murah

c. Arus proteksi yang dihasilkan tidak pernah salah arah, tidak memerlukan keahlian khusus

d. Instalasi relative lebih sederhana, sehingga tidak memerlukan keahlian khusus

e. Penghubung anoda telah terlindungi secara katodik.

\subsection{Anoda Korban}

Dalam desain perlindungan katodik, perhitungan akan dilakukan untuk memastikan anoda korban yang digunakan cukup tersedia untuk menyediakan total arus yang dibutuhkan untuk melindungi mooring buoy selama masa desainnya. Untuk menghitung kebutuhan anoda korban digunakan DNV RP (B401) [3]. Desain perlindungan katodik yang digunakan pada mooring buoy adalah Longated flush-mounted Type Z9.0HI (Welded Type) dengan ukuran ( $355 \mathrm{~mm}$ x $85 \mathrm{~mm}$ x $45 \mathrm{~mm}$ ) dan massa 9,5 kg dengan masa proteksi selama 5 tahun. Adapun data anoda pada Tabel 1. Berikut ini

Tabel 1. Data anoda desain [4]

\begin{tabular}{ll}
\hline Parameter & Nilai \\
\hline Desain umur anoda & 5 Tahun \\
\hline C) () & copyright is published under Lisensi Creative Commons Atribusi 4.0 Internasional.
\end{tabular}




\begin{tabular}{ll}
\hline Parameter & Nilai \\
\hline Jenis bahan anoda & Paduan Zinc Zn-Al-Cd \\
$\begin{array}{l}\text { Efesiensi Elektrokimia dalam air } \\
\text { laut pada suhu sekitar }\left(25^{\circ} \mathrm{C}\right)\end{array}$ & $780 \mathrm{~A}-\mathrm{h} / \mathrm{kg}$ \\
Ketebalan anoda & $45 \mathrm{~mm}$ \\
Panjang anoda & $355 \mathrm{~mm}$ \\
Lebar anoda & $85 \mathrm{~mm}$ \\
Massa anoda desain & $9,5 \mathrm{~kg}$ \\
Faktor pemanfaatan anoda & 0,85 \\
\hline
\end{tabular}

\section{HASIL DAN PEMBAHASAN}

Perhitungan kebutuhan anoda membutuhkan beberapa kriteria desain sesuai permintaan [1]. Kriteria tersebut antara lain adalah data propertis mooring buoy (Tabel 2), data lingkungan mooring buoy (Tabel 3) di lokasi pemasangan mooring buoy yaitu di Luwuk, Sulawesi Tengah dan data anoda yang akan dipasang (Tabel 1).

Tabel 2. Data propertis mooring buoy [4]

\begin{tabular}{lll}
\hline Parameter & Unit & Nilai \\
\hline Tinggi $(\mathrm{H})$ & $\mathrm{m}$ (meter) & 2,38 \\
Sarat $(\mathrm{T})$ & $\mathrm{m}$ (meter) & 2 \\
Diameter Atas & $\mathrm{m}$ (meter) & 3,2 \\
Diameter Alas & & 1,3 \\
Spesifikasi material & - & Marine Steel Plate \\
Tebal pelat & $\mathrm{mm}$ (millimeter) & 10 dan 12 \\
\hline
\end{tabular}

Tabel 3. Data lingkungan mooring buoy [4]

\begin{tabular}{lll}
\hline Parameter & Unit & Nilai \\
\hline Suhu air laut & ${ }^{\circ} \mathrm{C}$ & $25-31,5$ \\
\hline Massa jenis & $\mathrm{kg} / \mathrm{m}^{3}$ & 1025 \\
\hline
\end{tabular}

\subsection{Penentuan Total Anoda yang Dibutuhkan}

Kebutuhan anoda korban pada mooring buoy Pertamina Fuel Terminal Luwuk dengan menngunakan zinc anode (komposisi kimia paduan terdiri dari Cadmium 0,025 - 0,150\%, Pb/Lead 0,006\%, Copper 0,005\%, Iron 0,005\%, Aluminium 0,100 - 0,500\%, Silicon 0,125\% dan Zinc 98\%) dapat dihitung dengan menggunakan persamaan (4).

Luas permukaan mooring buoy dihitung dengan menggunakan pendekatan luas kerucut dan silinder seperti pada persamaan (3). Untuk koefisien faktor kerusakan lapisan dapat dilihat pada Tabel 4 yang mengacu pada Det Norske Veritas RPB401 tentang Cathodic Protection Design. Faktor kerusakan lapisan dapat dihitung dengan menggunakan persamaan (1).

1. Menghitung faktor kerusakan lapisan

$$
f_{c}(\text { terakhir })=k_{1}+k_{2} \times t f
$$

Jika nilai yang dihitung lebih dari $1, \mathrm{fc}=1$ harus digunakan di dalam desain. Persamaan diatas didasarkan untuk maksud desain saja, dan tidak diharapkan untuk memvisualisasi model sesungguhnya sebagai faktor kerusakan pelapis (coating breakdown) dimana desain sistem proteksi katodik melebih usia sistem pelapisan. Untuk nilai $\mathrm{k}_{1}$ dan $\mathrm{k}_{2}$ dapat dilihat pada tabel berikut:

Tabel 4. Konstanta (k1 dan k2) untuk perhitungan faktor kerusakan pelapis [5]

\begin{tabular}{lllll}
\hline \multirow{2}{*}{$\begin{array}{l}\text { Kedalaman } \\
(\mathrm{m})\end{array}$} & \multicolumn{4}{l}{ Kategori pelapis } \\
\cline { 2 - 5 } & $(\mathrm{k} 1=0,100)$ & $(\mathrm{k} 1=0,050)$ & $(\mathrm{k} 1=0,020)$ & $(\mathrm{k} 1=0,010)$ \\
& $\mathrm{k} 2$ & $\mathrm{k} 2$ & $\mathrm{k} 2$ & $\mathrm{k} 2$ \\
\hline $0<30$ & 0,100 & 0,030 & 0,015 & 0,012 \\
\hline
\end{tabular}




$\begin{array}{lllll}>30 & 0,050 & 0,020 & 0,012 & 0,012\end{array}$

2. Menghitung kebutuhan permintaan arus

Jika daerah masing-masing $(A c)$ tiap unit yang diproteksi dikalikan dengan desain arus densitas (ic) dan faktor kerusakan lapisan $(f c)$, maka akan diperoleh [5]:

$$
I c=A c \times f c \times i c
$$

Dimana $I c$ adalah permintaan arus, $A c$ area yang akan diproteksi, $f c$ faktor kerusakan lapisan dan ic faktor desain arus densitas, mengacu pada Tabel 5. Sedangkan area individu atau area yang akan diproteksi, diperoleh dengan menggunakan rumus:

$$
A c=((\pi \times r 2 \times t)+(\pi(r+R) b))
$$

Dimana $\pi=3.14$, $\mathrm{r}$ adalah panjang jari-jari alas mooring buoy, $\mathrm{R}$ adalah panjang jari-jari atas mooring buoy, $\mathrm{b}$ adalah panjang garis pelukis mooring buoy.

Tabel 5. Desain arus rata-rata densitas berdasarkan kedalam dan iklim [5]

\begin{tabular}{lllll}
\hline Kedalaman $(\mathrm{m})$ & \multicolumn{4}{l}{ Desain arus densitas (Rata-rata) dalam A/m2 } \\
\cline { 2 - 5 } & $\begin{array}{l}\text { Tropical } \\
\left(>20^{\circ} \mathrm{C}\right)\end{array}$ & $\begin{array}{l}\text { Sub Tropical } \\
\left(12-20^{\circ} \mathrm{C}\right)\end{array}$ & $\begin{array}{l}\text { Beriklim Sedang } \\
\left(7-12^{\circ} \mathrm{C}\right)\end{array}$ & $\begin{array}{l}\text { Sangat dingin } \\
\left(<7^{\circ} \mathrm{C}\right)\end{array}$ \\
\hline $0 \leq 30$ & 0,008 & 0,080 & 0,100 & 0,120 \\
\hline$>30$ & 0,006 & 0,070 & 0,080 & 0,100 \\
\hline
\end{tabular}

3. Menghitung kebutuhan massa anoda

Adapun untuk menghitung massa kebutuhan anoda korban digunakan persamaan seperti berikut [5]:

$$
m=\frac{I c \times T \times 8760}{\mu \times \varepsilon}
$$

Dimana m adalah massa anoda korban paduan seng (kg), Ic adalah kebutuhan arus proteksi (Ampere), $T$ adalah Umur proteksi (tahun), $\mathrm{T}=5$ tahun [6], $\mu$ adalah faktor guna anoda korban, $\mu=0.85, \varepsilon$ adalah Efesiensi elektrokimia $(\mathrm{Ah} / \mathrm{kg})$ dan $\varepsilon=780$, paduan seng.

Kebutuhan massa anoda yang telah dihitung menggunakan persamaan (4) kemudian dapat di tentukan kebutuhan anoda yang akan di pasang pada mooring buoy dengan menggunakan ukuran desain anoda. Sehingga jumlah anoda korban yang dibutuhkan dalam sistem proteksi katodik mooring buoy adalah:

$$
\Sigma A K=\frac{m}{m A K}(\text { buah })
$$

Dimana dimana $\Sigma$ AK adalah jumlah anoda korban, $m$ adalah massa anoda korban yang dibutuhkan, $\mathrm{m}_{\mathrm{AK}}$ adalah Massa per-unit anoda korban

4. Menentukan jarak antar anoda korban

Setelah di dapatkan jumlah anoda yang akan digunakan untuk memproteksi maka dapat ditentukan peletakan atau jarak antar anoda pada mooring buoy dengan menggunakan persamaan berikut.

$$
\mathrm{J} \text { AK }=\frac{K-(\text { Panjang Anoda } x \text { Jumlah Anoda })}{\Sigma \text { AKtotal }}
$$

Dimana $\mathbf{J}_{\mathrm{AK}}$ adalah jarak antar anoda korban (m), $\mathrm{K}$ adalah keliling mooring buoy (m) dan $\Sigma \mathrm{AK}_{\text {total }}$ adalah jumlah total anoda korban yang dipasang (buah). 


\subsection{Rekapitulasi Hasil Penelitian}

Berdasarkan persamaan yang digunakan dengan DNV RP (B401) “Cathodic Protection Design), didapatkan hasil sebagai berikut:

Tabel 6. Hasil perhitungan kebutuhan anoda

\begin{tabular}{llll}
\hline No & Deskripsi & Unit & Nilai \\
\hline 1 & Luas permukaan pipa & $\mathrm{m}^{2}$ & 34,054 \\
\hline 2 & Umur desain proteksi & Tahun & 5 \\
\hline 3 & Panjang anoda & $\mathrm{mm}$ & 355 \\
\hline 4 & Lebar anoda & $\mathrm{mm}$ & 85 \\
\hline 5 & Tebal anoda & $\mathrm{mm}$ & 45 \\
\hline 6 & Jarak antar anoda pada pelat lambung topside & $\mathrm{m}$ & 2,000 \\
\hline 7 & Jarak antar anoda pada pelat bottom swim lambung & $\mathrm{m}$ & 3,000 \\
\hline 8 & Total anoda yang dibutuhkan & buah & 6 \\
\hline
\end{tabular}

\subsection{Jarak Antar Anoda}

Posisi penempatan anoda korban berdasarkan hasil perhitungan dengan cara di las menggunakan elektroda kawat las untuk proses instalasi anoda korban dengan mooring buoy. Adapun posisi penempatan anoda korban yang dilakukan oleh pihak galangan saat mooring buoy melakukan reparasi dapat dilihat pada Gambar 4.6 berikut.

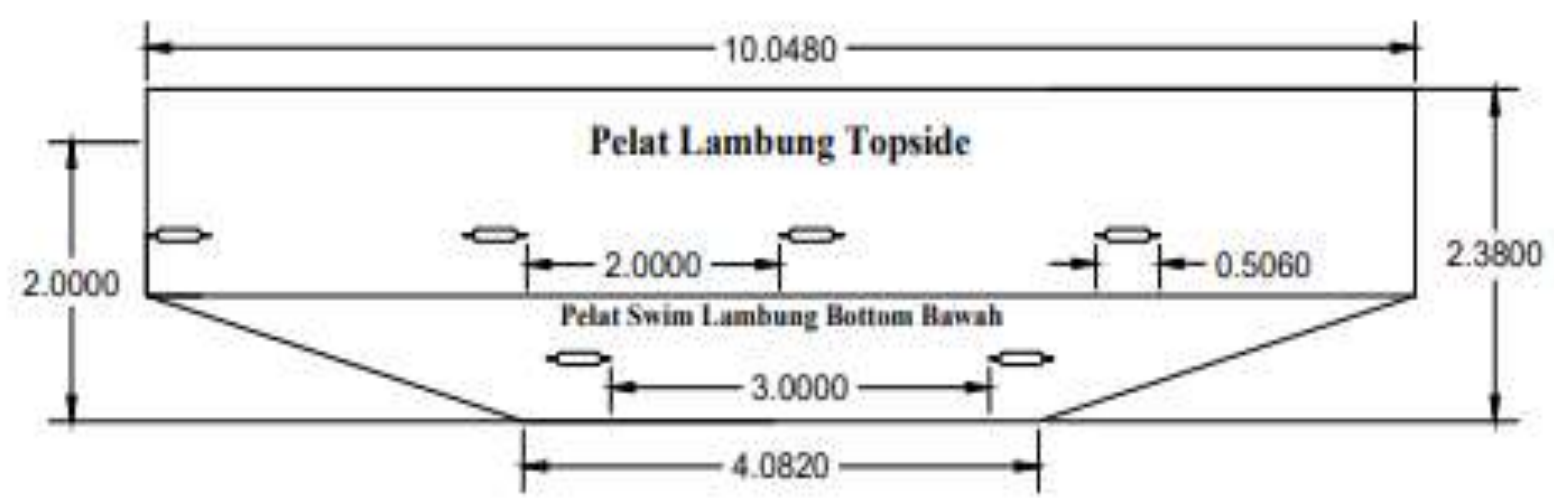

\section{Perencanaan Peletakan Zinc Anode}

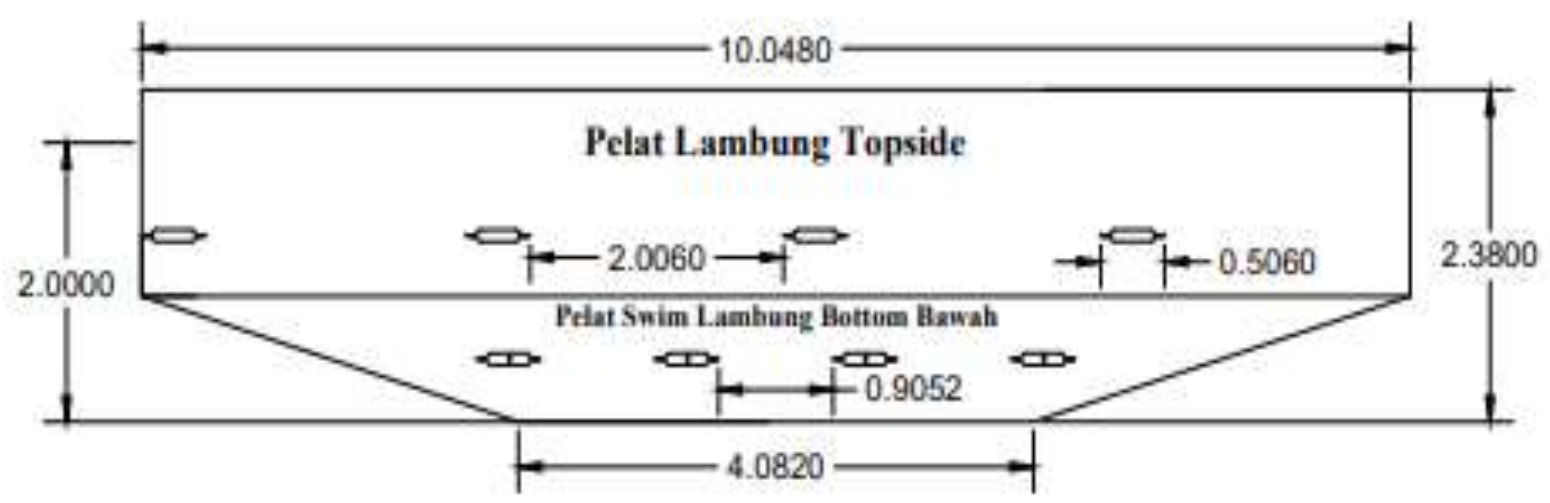

Gambar 2. Perencanaan dan eksisting peletakan anoda korban

\subsection{Rancangan Biaya yang Dibutuhkan}

copyright is published under Lisensi Creative Commons Atribusi 4.0 Internasional. 
Di bawah ini merupakan tabel hasil perhitungan analisa ekonomis untuk proteksi katodik anoda korban pada 1 (satu) buah mooring buoy.

Tabel 7. Perhitungan analisis ekonomi proteksi katodik pada mooring buoy [4]

\begin{tabular}{|c|c|c|c|c|c|}
\hline No. & Uraian & Satuan & Koefisien & Harga Satuan (Rp) & Jumlah Harga (Rp) \\
\hline 1 & 2 & 4 & 5 & 6 & 7 \\
\hline A. & \multicolumn{5}{|c|}{ Tenaga Kerja } \\
\hline 1 & Pekerja & $\mathrm{OH}$ & 2 & 70.000 & 140.000 \\
\hline 2 & Tukang Las & $\mathrm{OH}$ & 1.5 & 130.000 & 195.000 \\
\hline 3 & Mandor & $\mathrm{OH}$ & 0,25 & 150.000 & 37.500 \\
\hline \multicolumn{5}{|c|}{ Jumlah Harga Tenaga Kerja } & 372.500 \\
\hline B & \multicolumn{5}{|l|}{ Bahan } \\
\hline 1 & $\begin{array}{l}\text { Elektroda } \\
\text { kawat las }\end{array}$ & pcs & 10 & 3.000 & 30.000 \\
\hline 2 & Zinc Anode & pcs & 6 & 989.500 & 5.937 .000 \\
\hline \multicolumn{5}{|c|}{ Jumlah Harga Bahan } & 5.967 .000 \\
\hline $\mathrm{C}$ & Peralatan & & & & \\
\hline 1 & $\begin{array}{l}\text { Welding } \\
\text { Set }\end{array}$ & Set/hour & 1,5 & 114.000 & 171.000 \\
\hline \multicolumn{5}{|c|}{ Jumlah Harga Peralatan } & 171.000 \\
\hline D & \multirow{2}{*}{\multicolumn{4}{|c|}{$\begin{array}{l}\text { Jumlah Harga Tenaga Kerja, Bahan dan Peralatan }(\mathrm{A}+\mathrm{B}+\mathrm{C}) \\
\text { Overhead }+ \text { profit }(15 \%)\end{array}$}} & 6.510 .500 \\
\hline $\mathrm{E}$ & & & & & 976.575 \\
\hline $\mathrm{F}$ & \multicolumn{4}{|c|}{ Harga Satuan Pekerjaan (D+E) } & 7.487 .075 \\
\hline
\end{tabular}

Berdasarkan Tabel 7., diketahui biaya keseluruhan yang dibutukan dalam desain kebutuhan proteksi katodik anoda korban pada 1 (Satu) buah mooring buoy dengan diameter 3,200 $\mathrm{m}$ dan tinggi 2,380 $\mathrm{m}$ adalah Rp. 7.487.075 untuk memproteksi mooring buoy selama 5 tahun.

\section{KESIMPULAN}

Setelah melakukan pengolahan data mengenai perancangan sistem proteksi katodik anoda korban pada mooring buoy, di peroleh kesimpulan sebagai berikut:

1. Total anoda yang dibutuhkan untuk 1 (satu) buah mooring buoy dengan diameter 3,200 $\mathrm{m}$ dan tinggi 2,3800 m dan umur desain proteksi selama 5 tahun adalah 6 buah anoda dengan bentuk longated flushmounted (welded type) tipe Z9.0H1 dimensi anoda ( $355 \mathrm{~mm} \times 85 \mathrm{~mm} \times 45 \mathrm{~mm}$ ).

2. Jarak pemasangan antar anoda yang digunakan pada pelat lambung topside adalah 2,000 $\mathrm{m}$ dan untuk pelat bottom swim lambung adalah 3,000 m.

3. Biaya yang dibutuhkan untuk pembuatan proteksi katodik ini adalah sebesar Rp.7.487.075.

\section{UCAPAN TERIMA KASIH}

Ucapan terima kasih yang pertama ingin saya tujukan kepada Departemen Teknik Kelautan Universitas Hasanuddin yang telah membimbing penulis dalam menyelesaikan segala tugas dan penelitian selama perkuliahan. Kedua, ucapan terima kasih saya sampaikan kepada PT. Industri Kapal Indonesia yang telah membimbing dan mengarahkan penulis selama kerja praktek serta dalam pengambilan data dari proyek perusahaan yang pernah dikerjakan.

\section{DAFTAR PUSTAKA}

[1] N. Azisah, D. Paroka, and W. Wahyuddin, "Analisa Penempatan Dan Kebutuhan Proteksi Katodik Pada Sistem Pipa Gas Bawah Laut Offshore Dari Pulau Pemping Ke Tanjung Uncang Batam,” Zo. Laut J. 
Inov. Sains Dan Teknol. Kelaut., vol. I, no. 3, pp. 57-63, 2020, doi: 10.20956/zl.v1i3.11978.

[2] H. Palippui dan S. Ramadhan, "Analisa Kekuatan Struktur Barge Pada Proses Load Out Offshore Module (Top Side) dengan SPMT", zonalaut, vol. 1, no. 1, hlm. 1-5, Mar 2020.

[3] B. Sudjasta, P. J. Suranto, H. Setiani, P. Studi, T. Perkapalan, and J. Selatan, "Analisa Kebutuhan Pemasangan Zinc anode untuk Mencegah Korosi Pada Lambung Kapal Kapal General Cargo,” vol. 14, pp. 209-215, 2018.

[4] Windi Widianingrum, "Data Lapangan," Makassar, 2021.

[5] D. N. Veritas, "DNV Recommended Practice RP B401 Cathodic Protection Design." 1993.

[6] BKI, "Rules for Single Point Mooring," vol. IX, no. 38, 2012. 